Jurnal Pemberdayaan: Publikasi Hasil Pengabdian kepada Masyarakat

Vol. 2, No. 2,Agustus 2018, Hal. 283-290

ISSN: 2088 4559; e-ISSN: XXXX-XXXX

DOI:

\title{
PEMBINAAN BANK SAMPAH K3S JATIKUNING
}

\author{
Surahma Asti Mulasari ${ }^{1 \& 3}$, Sulistyawati $^{1 \& 3}$, Tri Wahyuni Sukesi ${ }^{1 \& 3}$, Fatwa Tentama $^{2 \& 3}$ \\ Fakultas Kesehatan Masyarakat Universitas Ahmad Dahlan Yogyakarta ${ }^{1}$ \\ Fakultas Psikologi Universitas Ahmad Dahlan Yogyakarta ${ }^{2}$ \\ Pusat Studi Wanita Universitas Ahmad Dahlan Yogyakarta ${ }^{3}$ \\ Email : surahma.mulasari@ikm.uad.ac.id
}

\begin{abstract}
ABSTRAK
Peran aktif masyarakat dibutuhkan untuk mengurangi jumlah sampah, memilah jenis sampah hingga berupaya menjadikan sampah bermanfaat. Bank sampah adalah tempat menabung sampah yang telah terpilah menurut jenis sampah dan mempunyai nilai ekonomis, selain itu bank sampah juga berfungsi untuk memberdayakan masyarakat agar peduli terhadap kebersihan. Tujuan dari kegiatan ini adalah untuk meningkatkan efektifitas bank sampah K3S agar lebih maju dan berkembang. Metode yang digunakan adalah dengan kegiatan sosialisasi berkelanjutan, pendampingan pelatihan serta kegiatan monitoring dan evaluasi kegiatan bank sampah. Hasil monitoring menunjukkan jumlah pembelian sampah setiap bulannya tidak tetap. Hal ini dikarenakan masih rendahnya kesadaran masyarakat untuk menabung sampah secara rutin, masyarakat sifatnya menabung jika mereka sempat saja. Dampak yang diharapkan dari kegiatan pengabdian ini adalah peningkatan kesadaran masyarakat untuk menabung di bank sampah secara rutin. Kesimpulan dari kegiatan pengabdian ini adalah kesadaran masyarakat akan tetap terjaga dengan metode sosialisasi berkelanjutan.
\end{abstract}

Kata Kunci: Bank Sampah, Ceramah, Pelatihan, Monitoring, Evaluasi

\begin{abstract}
Managing waste basically requires the active role of the community, especially in reducing the amount of waste, sorting out the type of waste to try to make waste useful. Waste bank is a place to save waste that has been sorted according to the type of waste, the waste saved in the waste bank is waste that has economic value, the waste bank also functions to empower the community to care about cleanliness. The purpose of this activity was to increase the effectiveness of the K3S waste bank to be more advanced and developing. The method used was continuous socialization activities, training assistance and monitoring and evaluation of waste bank activities. The monitoring results showed that the number of garbage purchases per month was not fixed, this was due to the low public awareness to save garbage on a regular basis, the community was saving if they just got it. The expected impact of this service activity is to increase public awareness to save at a garbage bank regularly. The conclusion of this activity was that public awareness will be maintained by the method of sustainable socialization.
\end{abstract}

Keywords: Waste Bank, Coaching

\section{PENDAHULUAN}

Sampah dipengaruhi oleh aktifitas manusia dan konsumsinya. Setiap aktifitas manusia menghasilkan sampah. Volume sampah berbanding lurus dengan tingkat 
konsumsi terhadap suatu barang yang gunakan setiap harinya. Demikian juga dengan jenis sampah sangat tergantung dari jenis material yang kita konsumsi (Mukono, 2006).

Manusia menghasilkan sampah dalam jumlah yang tidak sedikit pada setiap hari. Sampah dapat berasal dari berbagai kegiatan masyarakat seperti pertanian, pasar, rumah tangga, hiburan dan industri. Sampah yang dihasilkan dari kegiatan rumah tangga disebut sebagai sampah domestik (Sudiran, 2005). Jumlah pendudukan dan laju pertumbuhan penduduk perkotaan cenderung meningkat, hal tersebut menyebabkan sistem infrastruktur yang ada menjadi tidak memadai dan menyebabkan pemerintah harus bekerja keras dalam menangani permasalahan sampah (Riyanto, 2008).

Peran aktif masyarakat sangat dibutuhkan untuk mensukseskan pengelolaan sampah, terutama dalam mengurangi jumlah sampah, memilah jenis sampah serta mendaur ulang sampah. Keterlibatan masyarakat dalam proses pengelolaan sampah yaitu, mengupayakan agar sampah dikelola, dipilah dan diproses, dapat diawali dari lingkungan rumah tangga. Pengelolaan sampah akan mengurangi jumlah timbunan sampah yang harus dikumpulkan dan diangkut ke Tempat Pembuangan Sampah Sementara (Suwerda, 2012).

Pengelolaan sampah di berbagai daerah mengalami keberhasilan melalui program 3R (reuse, reduce, recycle), Hal ini menunjukkan bahwa kesadaran masyarakat akan kebersihan lingkungan semakin meningkat. Sampah tidak lagi dipandang barang yang tidak berguna, akan tetapi melulai program reuse, reduce dan recycle sampah menjadi suatu yang bermanfaat dan bernilai tambah atau memiliki nilai ekonomi (Peraturan Menteri Negara Lingkungan Hidup Republik Indonesia Nomor 13, 2012).

Undang-Undang No. 18 tahun 2008 yang mengatur tentang pengelolaan sampah pada pasal lima menyebutkan, bahwa pemerintah dan pemerintah daerah bertugas menjamin terselenggaranya pengelolaan sampah yang baik dan berwawasan lingkungan sesuai dengan tujuan sebagaimana disebutkan dalam undang-undang ini.

Pengelolaan sampah terdiri dari kegiatan memilah, penyimpanan sementara, mengumpulkan, mengangkut, mengelola, sampai membuang ke tempat pembuangan akhir. Pengelolaan sampah dengan menggunakan teknik sesuai prinsip kesehatan masyarakat dan prinsip kesehatan lingkungan. Kegiatan pengelolaan sampah menyangkut berbagai kegiatan, yaitu administrasi, manajemen, aspek legal, tekhnologi tepat guna, dan peran serta masyarakat. Pengelolaan sampah juga berkaitan dengan berbagai aspek, seperti aspek politik, ekonomis, sosiologis dan atau antropologis, demografis, geografis atau topografis, ekologi, dan juga amdal (Budiman, 2010). 
Masyarakat menganggap bahwa kegiatan pengolahan sampah hanya dianggap menjadi tanggung jawab pemerintah. Tanggung jawab tersebut dipegang oleh Dinas Kebersihan Kota/kabupaten. Pemahaman tersebut dipengaruhi pula oleh opini bahwa sampah identik dengan retribusi sampah. Masih banyak keluhan terhadap pelayanan pemerintah seperti keluhan lambannya petugas dalam pengumpulan sampah, sampah dibiarkan berserakan, banyak sampah keluar dari truk selama perjalanan, dan sebagainya. Pengolahan sampah bukan murni ekonomi dan bersifat komersial, tetapi juga merupakan aspek pelayanan umum yang merupakan tanggung jawab pemerintah atau publik (Karo, 2009).

Bank sampah merupakan suatu tempat untuk menabung sampah yang telah terpilah menurut jenis sampah. Bank sampah merupakan salah satu program pemberdayaan masyarakat. Sampah yang ditabung pada bank sampah adalah sampah yang memiliki nilai ekonomis, selain itu bank sampah juga berfungsi dalam memberdayakan masyarakat agar peduli terhadap kebersihan lingkungan (Wintoko, 2012). Bank sampah K3S merupakan bank sampah yang awalnya berdiri tahun 2014. Bank sampah ini terletak di Dusun Jatikuning, Ngoro-oro Patuk Gunungkidul yang pada awal mula berdiri dibina oleh Fakultas Kesehatan Masyarakat UAD. Pada tahun 2015, Pusat Studi Wanita (PSW UAD) ikut bergabung untuk mengembangkan . Sampai saat ini FKM dan PSW UAD konsisten untuk mendampingi Bank Sampah K3S dan juga Dusun Jatikuning dan dusun yang bersebelahan dengan Jatikuning yaitu Soka. Tujuan dari kegiatan pengabdian kali ini adalah untuk memastikan bahwa Bank Sampah K3S tetap bisa beroperasi dengan baik, menggairahkan kembali masyarkat untuk menabung di bank sampah, memberikan tambahan pengetahuan bagi pengelola bank sampah sehingga bank sampah K3S dapat secara konsisten beroperasi.

\section{METODE}

Metode yang diterapkan dalam kegiatan pengabdian masyarakat ini adalah dengan metode ceramah dan demonstrasi. Ceramah dilakukan kepada warga sebagai bentuk sosialisasi program berkelanjutan. Pelatihan dilakukan dengan pelatihan pembuatan web untuk meningkatkan pemasaran produk dan publikasi. Selain itu dilakukan kegiatan monitoring dan evaluasi kegiatan bank sampah K3S Jatikuning selama tahun 2018 untuk melihat efektifitas bank sampah. Materi yang disajika berkaitan dengan cara pengelolaan bank sampah, manajemen sampah dan materi tentang pemasaran yaitu berupa materi 
pembuatan web. Sedangkan materi demonstrasi berkaitan dengan pelatihan cara memasukkan konten promosi ke dalam web. Kegiatan pendampingan ini dilaksanakan pada tanggal 3-5 Oktober 2018. Sasaran dari kegiatan ini adalah pengelola atau pengurus bank sampah K3S Jatikuning.

\section{HASIL PEMBAHASAN DAN DAMPAK}

Kegiatan ceramah tentang bank sampah dan keuntungannya dilakukan dengan sasaran warga masyarakat Jatikuning. Kegiatan ini merupakan kegiatan sosialisasi berkelanjutan untuk meningkatkan pengetahuan masyarakat, sekaligus untuk menggugah kembali semangat masyarakat untuk menabung di bank sampah. Dampak dari kegiatan tersebut diharapkan di tahun berikutnya ada peningkatan jumlah nasabah dan jumlah tabungan sampah. Masyarakat yang diundang bersemangat dalam mengikuti kegiatan pengabdian kemungkinan disebabkan karena masyarakat telah lama beriteraksi dengan UAD dan telah mendapatkan banyak manfaat dari kegiatan-kegiatan pengadian yang dilakukan UAD di wilayah tersebut.

Kegiatan pelatihan dan demonstrasi yang diberikan adalah pelatihan pembuatan Web dan demonstrasi mengisi laman web tersebut. Pelatihan web bertujuan untuk membantu meningkatkan pendapatan pengelola bank sampah dan masyarakat. Adanya web bertujuan untuk membantu pemasaran produk-produk bank sampah K3S seperti kompos, kerajinan daur ulang, dan produk lainnya hasil dari masyarakat desa setempat. Dampak dari kegiatan ini nantinya adalah adanya peningkatan pengetahuan, perluasan pemasaran produk dan peningkatan pendapatan masyarakat di lokasi pengabdian.

Kegiatan dala pengabdian ini selanjutnya adalah kegiatan monitoring dan evaluasi bank sampah K3S sebagai bentuk pendampingan berkelanjutan dari UAD. Pendampingan berkelanjutan tersebut merupakan salah satu implementasi MOU antara UAD dengan desa binaan. Hasil monitoring dan evaluasi program bank sampah selama tahun 2018 dapat dilihat pada gambar berikut ini. 


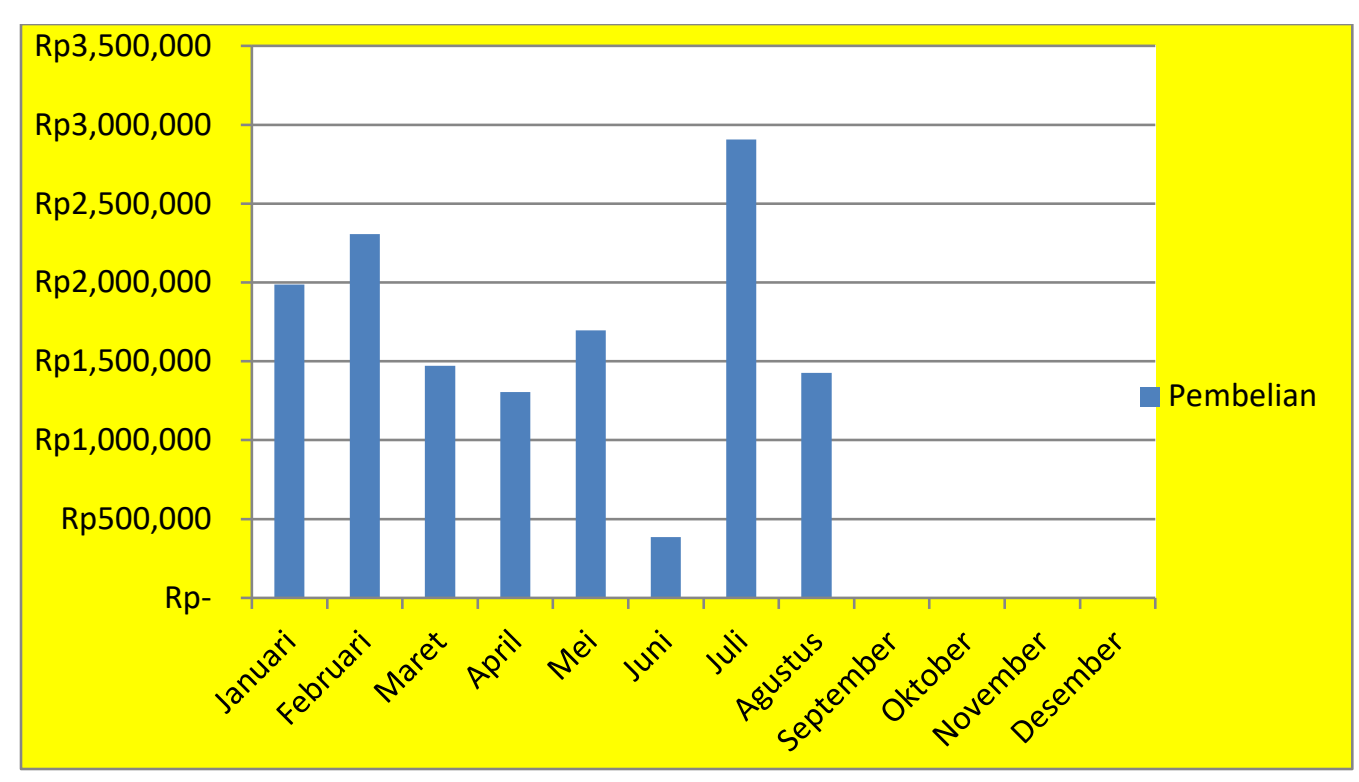

Grafik 1. Tabungan Nasabah Bank Sampah K3S Jatikuning Januari-Agustus tahun 2018

Berdasarkan grafik 1. dapat dilihat bahwa hasil pembelian sampah di bank sampah Jatikuning mengalami fluktuasi dari bulan ke bulan. Pada bulan Januari omset pembelian hampir mencapai Rp 2.000.000, kemudian pada Bulan Februari pembelian sampah mengalami kenaikan yaitu mencapai Rp 2.300.000. Pada bula Maret terjadi penurunan pembelian sampah yaitu hampir mencapai Rp 1.500.000, kemudian pada bulan April mengalami penurunan lagi, dari Rp 1.500.000 turun menjadi Rp 1.300.000. Bulan Mei pembelian sampah mengalami peningkatan yaitu mencapai sekitar Rp 1.700 .000 selanjutnya pada Bulan Juni pembelian sampah mengalami penurunan yaitu hanya melakukan pembelian sekitar Rp 400.000. Kenaikan drastis terjadi pada Bulan Juli, dari Rp 400.000 meningkat menjadi sekitar Rp 2.900.000, pada Bulan Juli juga merupakan bulan dengan pembelian tertinggi selama tahun 2018. Setelah mengalami peningkatan drastis, terjadi penurunan drastis pada bulan Agustus yaitu pembelian sampah hanya sekitar Rp 1.400.000, selisih dengan bulan sebelumnya mencapai sekitar Rp 1.500.000. Jika dihitung keseluruhan jumlah pembelian sapah di bank sampah K3S Jatikuning selama delapan bulan di tahun 2018 menapai Rp 13.481.767. Berdasarkan jumlah tersebut dapat diketahui rata-rata pembelian sampah di bank sampah K3S Jatikuning setiap bulan tahun 2018 adalah Rp 1.685.220, angka ini merupakan angka yang cukup tinggi.

Angka pembelian yang tidak tetap (naik turun) tersebut dapat disebabkan oleh banyak faktor yang mempengaruhi. Beberapa faktor yang mempengaruhi antara lain ketertiban atau keteraturan nasabah dalam menabung atau menyetor sampah yang dimilikinya, karena 
sebagian besar masyarakat sifatnya menabung berdasarkan kemauan sendiri, menyesuaikan aktivitas mereka, jadi sebagian besar masyarakat menabung hanya saat mereka sempat atau memiliki waktu saja. Hal ini dapat disebabkan karena kurangnya kesadaran nasabah (masyarakat) untuk menyetor atau menabung sampah seara rutin atau teratur. Hal lain disebabkan karena jumlah sampah yang dimiliki nasabah (masyarakat) jumlahnya tidak tetap atau tidak sama dari bulan ke bulan, karena kebutuhan atau konsumsi masyarakat juga tidak selalu sama pada setiap harinya. Pada saat angka pembelian meningkat, juga dapat disebakan karena adanyaq nasabah baru yang ikut berpartisipasi dalam program bank yang pada awalnya belum merupakan anggota nasabah aktif.

Faktor-faktor tersebut yang akan menjadi bahan evaluasi dan menjadi bahan perbaikan untuk dapat menemukan solusi-solusi dalam mengatasi masalah-masalah tersebut, sehingga dapat meningkatkan partisipasi masyarakat yang lebih aktif lagi dalam menabung di bank sampah. Salah satu solusi yang dapat ditawarkan adalah dengan melakukan pengambilan sampah keliling, hal ini dapat dilakukan untuk mengatasi masalah jika masyarakat tidak sempat mengantarkan sampahnya ke bank sampah, maka dari itu, untuk memaksimalkan pembelian setiap bulannya pengelola dapat menyediakan fasilitas dengan membentuk tim yang melakukan pengambilan sampah keliling dari rumah ke rumah.

Menabung di bank sampah, berarti masyarakat telah berpartisipasi dalam program daur ulang. Banyak manfaat yang diperoleh jika masyarakat mau seara rutin menabung di bak sampah, tidak hanya pada bidang ekonomi, kesehatan lingkungan juga menjadi salah satu manfaat menabung di bank sampah. Dalam penelitiannya, Selomo (2016) mengatakan bahwa bank sampah merupakan kegiatan bersifat social engineering yang mengajarkan masyarakat untuk memilah sampah serta menumbuhkan kesadaran masyarakat dalam pengelolaan sampah secara bijak sehingga dapat mengurangi sampah yang diangkut ke TPA (Tempat Pembuangan Akhir). Pembangunan bank sampah merupakan momentum awal membina kesadaran kolektif masyarakat untuk memulai memilah, mendaur ulang dan memanfaatkan sampah karena sampah mempunyai nilai jual yang cukup baik.

Asteria (2016), dalam penelitiannya mengatakan bahwa pemberdayaan warga untuk membentuk pengetahuan dan keterampilan warga sehingga mampu memilah sampah organik dan non organik. Manfaat dari kemampuan warga mengelola sampah dengan menerapkan prinsip 4R dan menabung ke bank sampah telah memberikan manfaat 
langsung, tidak hanya secara ekonomi, juga terwujudnya kesehatan lingkungan, dengan kondisi komunitas yang bersih, hijau, nyaman, dan sehat.

Dalam kegiatan ini, masyarakat juga diberikan materi yang berkaitan dengan cara pengelolaan bank sampah, manajemen sampah dan materi pemasaran melalui web. Kegiatan ini disampaikan dengan metode ceramah, karena metode ceramah adalah salah satu metode yang efektif dalam suatu proses atau metode promosi kesehatan. Metode ceramah adalah suatu cara dalam menerangkan dan menjelaskan suatu ide, pengertian atau pesan secara lisan kepada sekelompok sasaran sehingga memperoleh informasi mengenai kesehatan (Notoatmodjo, 2010). Menurut Asfar (2018) yang meneliti tentang pengaruh penyuluhan kesehatan terhadap tingkat pengetahuan dan sikap memperoleh hasil bahwa terdapat peningkatan nilai rata-rata sikap setelah pemberian penyuluhan kesehatan, dikarenakan pemberian penyuluhan dilakukan dengan metode ceramah disertai media leaflet, sehingga segala pesan atau informasi yang disampaikan dapat diterima dengan baik dan jelas oleh pendengar.

Dengan adanya kegiatan pembinaan serta dilakukan kegiatan monitoring dan evaluasi ini, pengelola dapat mengetahui seberapa berjalannya bank sampah K3S Jatikuning ini, apa kendala yang didapatkan sekaligus dapat menemukan solusi bersama dari masalah yang ada. Dengan hal ini, diharapkan dapat membantu pengelola dalam mengelola bank sampah K3S Jatikuning sehingga bank sampah menjadi lebih maju dan berkembang.

\section{SIMPULAN}

Pelaksanaan kegiatan pembinaan telah berjalan dengan lancar. Intervensi dilakukan dengan kegiatan ceramah, pelatihan dan demonstrasi, serta pelaksanaan kegiatan monitoring dan evaluasi sebagai bentuk pendampingan dan implementasi MOU. Dengan diadakannya kegiatan pengabdian ini diharapkan dapat menjadi bahan evaluasi dan perbaikan sehingga bank sampah K3S Jatikuning menjadi lebih maju dan berkembang.

\section{DAFTAR PUSTAKA}

Asfar, A., Asnaniar, W. O. S,. 2018. Pengaruh Penyuluhan Kesehatan Terhadapa Tingkat Pengetahuan dan Sikap Tentang Penyakit HIV/AIDS di SMP Baznas Provinsi Sulawesi Selatan. Journal of Islamic Nursing., 3(1), 26-31.

Asteria, D. Heruman, H., 2016. Bank Sampah Sebagai Alternatif Strategi Pengelolaan Sampah Berbasis Masyarakat di Tasikmalaya. Jurnal Manusia dan Lingkungan. Vol: 
23. No: 1. Hal: 136-141

Budiman, 2010, Ilmu Kesehatan Masyarakat Dalam Konteks Kesehatan Lingkungan, Buku Kedokteran EGC, Jakarta. Hal.129.

Mukono, H. J., 2006, Prinsip Dasar Kesehatan Lingkungan, Airlangga University Press, Surabaya, Vol. 2, Hal. 157-158.

Notoatmodjo S. 2010. Ilmu Perilaku Kesehatan. Jakarta:PT Rineka Cipta

Peraturan Menteri Negara Lingkungan Hidup Republik Indonesia Nomor 13, 2012, Tentang Pedoman Pelaksanaan Reduce, Reuse, Dan Recycle Melalui Bank Sampah.

Riyanto, B., 2008, Prospek Pengelolaan Sampah Nonkonvensional Di Kota Kecil (Studi Kasus: Kabupaten Gunungkidul), Tesis, Pascasarjana, Universitas Diponegoro, Semarang, Hal. 11.

Selomo, M. Birawida, A.B., Mallongi, A., Muammar., 2016. Bank Sampah Sebagai Salah Satu Solusi Penanganan Sampah di Kota Makassar. Jurnal MKMI. Vol: 12. No: 4. Hal: 232-240.

Sudiran, 2005, "Instrumen Sosial Masyarakat Karangmumus Kota Samarinda Dalam Penanganan Sampah Domestik”, Journal Makara, Sosial Humaniora, Vol.9, Hal. 16-17.

Suwerda, B., 2012, Bank Sampah Kajian Teori, Buku I, Penerbit Werda Press, Yogyakarta. Hal. 3, 5, 9-11, 24. 